\title{
Impacts of Tooth Loss on OHRQoL in an Adult Population in Cape Town, South Africa
}

\author{
Faheema Kimmie-Dhansay ${ }^{1,2, * \mathbb{C}}$, Carla Cruvinel Pontes ${ }^{2}$, Usuf M. E. Chikte ${ }^{2}$, Albert Chinhenzva ${ }^{2}$, \\ Rajiv T. Erasmus ${ }^{3}\left(\mathbb{D}\right.$, Andre Pascal Kengne ${ }^{2,4}(\mathbb{D})$ and Tandi E. Matsha ${ }^{5}$ \\ 1 Division of Research and Postgraduate Studies, Faculty of Dentistry, University of the Western Cape, \\ Cape Town 7505, South Africa \\ 2 Division of Health Systems and Public Health, Department of Global Health, Stellenbosch University, \\ Cape Town 7505, South Africa; pontescarla@hotmail.com (C.C.P.); umec@sun.ac.za (U.M.E.C.); \\ albertc1980@gmail.com (A.C.); andre.kengne@mrc.ac.za (A.P.K.) \\ 3 Division of Clinical Pathology, Stellenbosch University, Cape Town 7505, South Africa; rte@sun.ac.za \\ 4 Non-Communicable Diseases Research Unit, South African Medical Research Council, \\ Cape Town 7505, South Africa \\ 5 SAMRC/CPUT/Cardiometabolic Health Research Unit, Department of Biomedical Sciences, \\ Cape Peninsula University of Technology, Cape Town 7535, South Africa; matshat@cput.ac.za \\ * Correspondence: fkimmie@uwc.ac.za; Tel.: +2-7021-9373-000
}

check for updates

Citation: Kimmie-Dhansay, F.; Pontes, C.C.; Chikte, U.M.E.; Chinhenzva, A.; Erasmus, R.T.; Kengne, A.P.; Matsha, T.E. Impacts of Tooth Loss on OHRQoL in an Adult Population in Cape Town, South Africa. Int. J. Environ. Res. Public Health 2021, 18, 4989. https:// doi.org/10.3390/ijerph18094989

Academic Editor: Chun-Hung Chu

Received: 12 March 2021

Accepted: 30 March 2021

Published: 8 May 2021

Publisher's Note: MDPI stays neutral with regard to jurisdictional claims in published maps and institutional affiliations.

Copyright: (c) 2021 by the authors. Licensee MDPI, Basel, Switzerland. This article is an open access article distributed under the terms and conditions of the Creative Commons Attribution (CC BY) license (https:/ / creativecommons.org/licenses/by/ $4.0 /)$.

\begin{abstract}
Background: Tooth loss is an important component of the global burden of oral disease, greatly reducing the quality of life of those affected. Tooth loss can also affect diet and subsequent incidences of lifestyle diseases, such as hypertension and metabolic syndromes. This study aimed to evaluate the oral health-related quality of life (OHRQoL) score using the oral impacts on daily performance (OIDP) index in relation to tooth loss patterns among adults. (2) Methods: From 2014 to 2016, a cross-sectional study was conducted on adults living in Bellville South, Cape Town, South Africa. The OHRQoL measure was used to evaluate the impact of tooth loss. (3) Results: A total of 1615 participants were included, and $143(8.85 \%)$ had at least one impact (OIDP > 0). Males were less likely to experience at least one impact compared to the females, $\mathrm{OR}=0.6,95 \%$ C.I.: 0.385 to 0.942 , $p=0.026$. Those participants who did not seek dental help due to financial constraints were 6.54 (4.49 to 9.54) times more likely to experience at least one impact, $p<0.001$. (4) Conclusions: Tooth loss did not impact the OHRQoL of these subjects. There was no difference in the reported odds for participants experiencing at least one oral impact with the loss of their four anterior teeth, the loss of their posterior occlusal pairs, or the loss of their other teeth.
\end{abstract}

Keywords: quality of life; tooth loss; adults; self-concept; noncommunicable diseases

\section{Introduction}

Tooth loss has been studied for decades and there are many different causes attributed to it, such as dental decay, periodontal disease, and trauma [1]. Dental caries and periodontal disease are known to be related to social and behavioural factors [1] and diet [2]. The lack of access to dental care [3], tobacco use [1], and poor oral health knowledge and oral hygiene practices [4] also play a crucial role in the progression of these oral conditions.

There are local and systemic sequelae to tooth loss [5,6]. Local complications of tooth loss can result in aesthetic and functional complications $[7,8]$. Aesthetic complications can affect speech [9] and lead to negative psychological consequences [10]. In addition, the loss of any teeth in the mouth can lead to malocclusion. Malaligned teeth can be difficult in terms of adequate plaque control, thus harbouring bacteria that can result in dental caries and periodontitis [11]. In addition, the loss of anterior teeth can negatively influence the ability to find work and can have an impact on daily living [12]. Missing teeth leads to the resorption of the alveolar bone, leading to ill-fitting dentures, which can also cause a poorer oral health-related quality of life (OHRQoL) [13]. The loss of teeth can also result in 
debilitating tempero-mandibular joint (TMJ) disorders [14]. Tooth loss has been implicated in a poorer OHRQol for different populations across the globe $[15,16]$.

Systemic complications of tooth loss include gastroesophageal reflux disease [17] and an increased risk for diabetes mellitus [18]. The management of tooth loss includes both fixed and removable options. Dental implants are not readily available to the larger South African population due to their high cost. For this reason, a significant proportion of edentulous or partially edentulous people living in this country wear removal dentures. Many have their dentures constructed by unqualified technicians at a fraction of what it may cost if constructed by qualified oral health professionals. The consequences are often ill-fitting dentures that are prone to unwanted complications, such as localised trauma and denture stomatitis. The best way to avoid these complications is to prevent tooth loss.

South Africa is a country known internationally for its deep history of apartheid, which has, to date, resulted in one of the highest rates of inequality in the world [19]. This has translated into major inequalities in healthcare and a lack of access to healthcare for the majority of the country's population. Although there have been a few studies evaluating the OHRQoL in South Africa, this is the first study undertaken to evaluate the impact that tooth loss has on the OHRQoL [20,21]. The aim of this study is to assess the impact of tooth loss on the OHRQoL in an adult population in Cape Town, South Africa.

\section{Materials and Methods}

\subsection{Study Design and Participants}

This cross-sectional study was conducted from 2014 to 2016 as part of the Cape Town Vascular and Metabolic Health (VHM) study, which has been previously described in detail [22]. The Ethics Committee approved the study of the Faculty of Health and Wellness Sciences of the Cape Peninsula University of Technology (N14/01/003a). All the procedures performed in the studies involving human participants followed the institutional and/or national research committee's ethical standards and the 1964 Helsinki declaration and its later amendments or comparable ethical standards.

Informed consent was obtained from all the individual participants included in the study. A non-probabilistic sampling technique was employed in which adults who lived in Bellville South, Cape Town, South Africa and met the inclusion criteria were included in the study. Adults over the age of 18 years, nonpregnant women, people with no previous history of diabetes mellitus, and participants who had the ability to give informed consent to engage in the study and who had the willingness to join in the study met the inclusion criteria. Individuals who required prophylactic antibiotics, participants undergoing renal dialysis, and participants with cancer were excluded. A multistage random sampling technique was employed and previously described [23]. The sample size was based on the prevalence of $33 \%$ of difficulty in the eating domain of the oral impacts on daily performance (OIDP) tool in a previous study [20], and was estimated to be 339. South Africa is classified as an upper-middle-income country, with the highest level of inequality globally, having a Gini coefficient of 0.63 [24]. This study is compliant with the Strengthening the Reporting of Observational Studies in Epidemiology (STROBE) report [25].

\subsection{Clinical Examination and OIPD Tool}

A trained and calibrated dental examiner assessed the decayed, missing, and filled tooth (DMFT) score, and the OIDP score was recorded by trained examiners. The OIDP tool was offered to the participants in English or Afrikaans, as the community was bilingual.

The OIPD was evaluated across ten domains: eating, speaking, cleaning teeth, light activities, vigorous activities, sleeping, relaxing, smiling, emotional state, and social contact, and the time frame was the previous six months. The OIDP score was calculated using the product of the frequency of the impact and the severity of the impact. The frequency of the impact was recorded as a 5-part Likert-type scale of every or nearly every day; once or twice a week; 3-4 times a week; once or twice a month and less than once a month. The severity of the impacts was reported as a 4-part Likert-type scale of no effect, mild effect, 
moderate effect, and severe effect. The OIDP domain score was calculated as the product of the severity of the impact and the frequency of each domain's impact. The overall OIDP score was the sum of the OIDP domain scores across the ten domains divided by the maximum domain score (20) multiplied by 100 [26]. The OIDP category was dichotomised as the OIDP score being above 1 and was classified as having at least one dental impact.

Posterior occluding pairs (POPs) were defined as the number of pairs of premolar and molar teeth occluding with each other (whether the maxillary premolars and molars are occluding with their maxillary partners). The POPs was further dichotomised into groups of less than four occluding pairs and groups of greater than or equal to four occluding pairs for the analysis.

The number of functional teeth was described according to the number of teeth missing. Having less than ten teeth missing was categorised as a functional dentition, having between 10 and 20 missing teeth was classified as moderate tooth loss, and having between 20 and 27 missing teeth was regarded as severe tooth loss. Being fully edentulous was considered when at least 28 teeth were missing, as reported in Stock et al. [27]. The missing contribution was characterised by having at least one missing tooth. In Cape Town, South Africa, there is a tendency for this study's population to extract their four maxillary anterior teeth. We have thus classified anterior tooth loss prevalence as a participant having all four maxillary anterior teeth extracted.

Denture status was classified as having a denture or not having a denture. The brushing frequency was determined as brushing teeth or dentures/gums once a day, twice a day, and more than twice a day. The DMFT score was defined using the WHO's Oral Basic Surveys Method 5th edition [28].

The participants' self-reported health statuses were classified as bad, poor, fair, good, or excellent. The participants were also asked about whether they sought dental care or not due to a lack of funds.

\subsection{Statistical Considerations}

The nominal, dichotomous, and ordinal variables were initially displayed as percentages and frequencies, with group comparisons based on the chi-square test. An unadjusted and adjusted logistic regression was run to determine the associations between the variables. All the missing data were excluded. A $p$-value $<0.05$ was used to characterise statistically significant results. All data were analysed using StataCorp. 2017 (Stata Statistical Software: Release 15. StataCorp LLC: College Station, TX, USA).

\section{Results}

A total of 1976 participants was initially included in the study, of which 101 were excluded due to missing data (Figure 1). The final analytic sample of 1615 participants included 408 males (25.3\%) and 1207 females (74.7\%). The median age was 52 (39 to 61, Table 1). There was no statistically significant difference between the gender and the age categories $(p=0.663)$. The median number of total teeth and missing teeth in the nonedentulous patients was 20 (14 to 24 ) and 8 (4 to 14), respectively. The median number of posterior occlusal pairs was four (one to four, Table 1 ).

In total, 735 participants $(45.4 \%)$ of the study population had no natural teeth. Just over a third of the participants $(35 \% ; n=580)$ had a functional dentition. Approximately $50 \%(n=822)$ of the population brushed their teeth/dentures at least once a day and $124(7.9 \%)$ reported brushing their teeth/dentures more than two times a day (Table 2). More than $40 \%(n=661)$ had at least one set of posterior occlusal pairs, and of the dentate individuals with at least one missing tooth, just over $82 \%(n=663)$ had no dentures (Table 2). For dentate individuals, $32.3 \%(n=274)$ had all four maxillary anterior teeth missing (Table 3). 


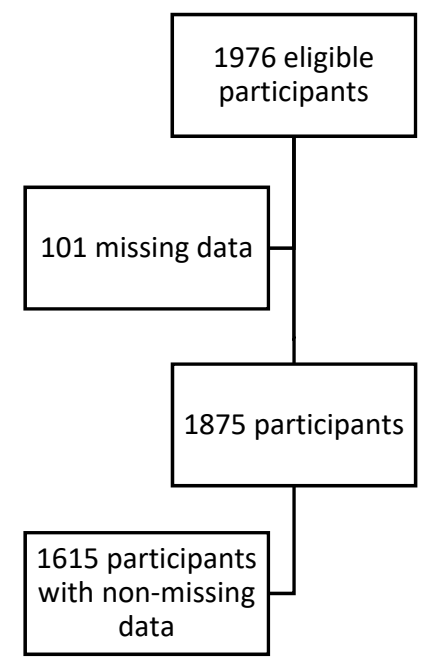

Figure 1. A flowchart of the number of participants.

Table 1. Baseline Demographics.

\begin{tabular}{lcc}
\hline Variable & $\boldsymbol{n ( \% )}$ & Median (Interquartile Range (IQR)) \\
\hline Gender $(n=1615)$ & & \\
Female & $1207(74.7)$ & \\
Male & $408(25.3)$ & $52(39$ to 61$)$ \\
Age & & $20(14$ to 24$)$ \\
Total no. of teeth present & $8(4$ to 14$)$ \\
No. of missing teeth & $4(1$ to 4$)$ \\
No. of posterior occlusal pairs & $4(0$ to 4$)$ \\
No. of maxillary anterior teeth lost & & \\
\hline
\end{tabular}

Table 2. The distribution of OIDP according to various clinical outcomes.

\begin{tabular}{|c|c|c|c|}
\hline Variable & OIDP $\%>0$ & \multicolumn{2}{|c|}{$p$-Value } \\
\hline \multicolumn{4}{|l|}{ Gender } \\
\hline Male & $408(25.3)$ & $25(6.1)$ & \\
\hline Female & $1207(74.7)$ & $118(9.8)$ & $0.025 *$ \\
\hline \multicolumn{4}{|l|}{ Dentition status } \\
\hline Edentulous & $733(45.4)$ & $53(7.2)$ & \multirow{4}{*}{0.124} \\
\hline Severe tooth loss & $56(3.5)$ & $8(14.3)$ & \\
\hline Moderate tooth loss & $246(15.2)$ & $23(9.4)$ & \\
\hline Functional dentition & $580(35.9)$ & $59(10.2)$ & \\
\hline \multicolumn{4}{|l|}{ Number of posterior occlusal pairs } \\
\hline 0 & $954(59.1)$ & $76(7.9)$ & \multirow{2}{*}{0.131} \\
\hline$\geq 1$ & $661(40.9)$ & $67(10.1)$ & \\
\hline \multicolumn{4}{|c|}{ Dentures (for NE subjects (MT > 0 and MT < 28) $(n=807)$} \\
\hline No denture & $663(82.2)$ & $69(10.4)$ & \multirow{2}{*}{0.622} \\
\hline Any type of denture & $144(17.8)$ & $17(11.8)$ & \\
\hline \multicolumn{4}{|l|}{ Brush } \\
\hline Once a day & $822(50.9)$ & $59(7.2)$ & \multirow{3}{*}{$<0.001$ * } \\
\hline Two times a day & $669(41.4)$ & $59(8.8)$ & \\
\hline More than two times a day & $124(7.7)$ & $25(20.2)$ & \\
\hline
\end{tabular}


Table 2. Cont.

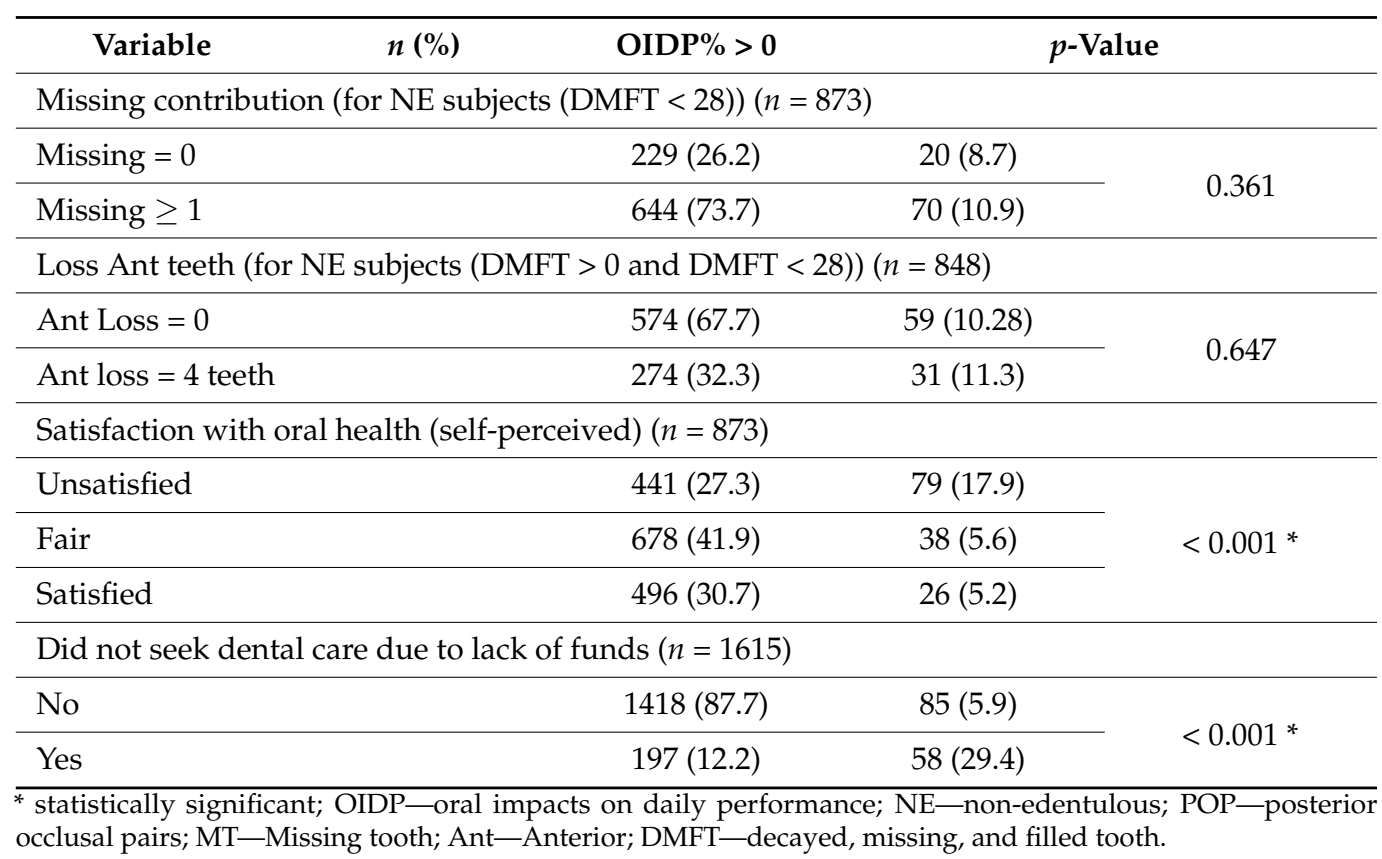

Table 3. The logistic regression for OIDP scores with clinical parameters (OR with $95 \%$ confidence intervals).

\section{Logistic Regression between OIDP Score $>1$ and Clinical Parameters}

\section{Unadjusted Odds} Ratio (OR) (95\% Confidence Interval)

\begin{tabular}{|c|c|c|c|c|c|}
\hline Age & & 0.99 (0.986 to 1.00$)$ & 0.747 & & \\
\hline $\begin{array}{l}\text { Total number of } \\
\text { teeth present }\end{array}$ & & 0.97 (0.944 to 1.00$)$ & 0.118 & & \\
\hline $\begin{array}{l}\text { Total number of } \\
\text { missing teeth }\end{array}$ & & 1.03 (0.994 to 1.06$)$ & 0.118 & & \\
\hline $\begin{array}{l}\text { Number of posterior } \\
\text { occlusal pairs }\end{array}$ & & 0.93 (0.863 to 1.00$)$ & 0.085 & & \\
\hline $\begin{array}{l}\text { Number of lost } \\
\text { maxillary anterior teeth }\end{array}$ & & $1.03(0.917$ to 1.16$)$ & 0.607 & & \\
\hline \multirow[t]{2}{*}{ Gender } & Male & $0.60(0.385$ to 0.942$)$ & $0.026 *$ & $0.61(0.379$ to 0.975$)$ & $0.039 *$ \\
\hline & Female & 1 & & 1 & \\
\hline \multirow[t]{4}{*}{ Dentition status } & Edentulous & 1 & & & \\
\hline & Severe tooth loss & 2.14 (0.962 to 4.754$)$ & 0.062 & & \\
\hline & Moderate tooth loss & 1.32 (0.793 to 2.209$)$ & 0.284 & & \\
\hline & Functional dentition & 1.45 (0.986 to 2.142$)$ & 0.059 & & \\
\hline \multirow[t]{2}{*}{ Number of POP pp } & 0 & 1 & & & \\
\hline & $\geq 1$ & $0.94(0.570$ to 1.551$)$ & 0.808 & & \\
\hline \multirow[t]{2}{*}{ Dentures } & No denture & 1 & & & \\
\hline & Any type of denture & 1.15 (0.655 to 2.026$)$ & 0.622 & & \\
\hline \multirow[t]{3}{*}{ Brush } & Once a day & 1 & & 1 & \\
\hline & Two times a day & 1.42 (0.878 to 2.285$)$ & 0.154 & $1.39(0.927$ to 2.074$)$ & 0.111 \\
\hline & $\begin{array}{l}\text { More than two times } \\
\text { a day }\end{array}$ & 3.37 (1.713 to 6.613$)$ & $<0.001 *$ & 3.09 (1.765 to 5.429$)$ & $<0.001 *$ \\
\hline
\end{tabular}


Table 3. Cont.

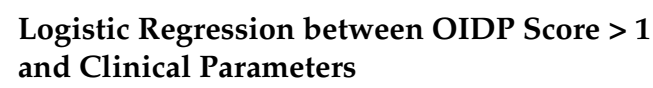

\begin{tabular}{|c|c|c|c|c|c|}
\hline $\begin{array}{l}\text { Loss of maxillary } \\
\text { anterior teeth pp }\end{array}$ & Ant Loss $=0$ & 1 & & & \\
\hline & Ant loss $\geq 1$ & 1.11 (0.702 to 1.765$)$ & 0.647 & & \\
\hline \multirow[t]{3}{*}{$\begin{array}{l}\text { Satisfaction with oral } \\
\text { health (self-perceived) }\end{array}$} & Unsatisfied & 3.94 (2.481 to 6.273$)$ & $<0.001 *$ & 3.94 (2.419 to 6.429$)$ & $<0.001$ * \\
\hline & Fair & 1.07 (0.642 to 1.792$)$ & 0.787 & 1.38 (0.805 to 2.349$)$ & 0.243 \\
\hline & Satisfied & 1 & & 1 & \\
\hline \multirow{2}{*}{$\begin{array}{l}\text { Did not seek dental } \\
\text { care due to lack } \\
\text { of funds }\end{array}$} & No & 1 & & 1 & \\
\hline & Yes & 6.54 (4.490 to 9.538$)$ & $<0.001 *$ & 5.59 (3.768 to 8.321$)$ & $<0.001$ * \\
\hline
\end{tabular}

The corrected item correlation ranged from 0.24 to 0.92 , which is above the minimum recommended level of 0.20 to include items in the scale and which meets the stringent criterion of item convergent validity of $>0.40$. The highest Cronbach's alpha of the scale was 0.96 , with alpha values implying an excellent internal consistency.

A total of $143(8.85 \%)$ individuals reported at least one impact. There was no difference in the OHRQoL for patients of different ages, nor for patients' number of teeth present, number of missing teeth, number of posterior occlusal pairs, or number of lost maxillary anterior teeth (Table 3). There was no difference in the type of dentition status (functional versus edentulous status), nor the presence of dentures (Table 3) in relation to the OHRQoL.

\section{Discussion}

The aim of this study is to assess the impact of tooth loss on the OHRQoL in an adult population in Cape Town, South Africa.

To our knowledge, this is the first study conducted in adults in South Africa and Africa that also reports the impact of tooth loss on the OHRQoL. In the present study, $8.85 \%$ of the participants reported having had at least one impact in the previous 6 months.

There was no difference in the oral health-related quality of oral life for subjects with and without the loss of the anterior teeth, with and without the loss of the posterior occlusal pairs, or with different numbers of missing teeth. According to Tan et al. [29], the presence of dental disease and poor health does not always imply a poorer quality of life, and the adaptive capacity and personal characteristics of the individual need to be considered. In a meta-analysis on the effect of tooth loss in the OHRQoL, Gerritsen et al. [15] found a significant correlation between tooth loss, a lower number of occluding pairs, and the loss of the anterior occlusal pairs and impaired OHRQoL, and the authors highlighted that the location and the distribution of lost teeth influenced the severity of the impairment. The current results are not in agreement with the results from this meta-analysis, considering that there is no difference in the odds of having at least one impact in participants who had lost all their anterior teeth. There was no difference in the oral impacts for the participants who had no posterior occlusal pairs compared to the participants with more than one occlusal pair present. The population of Cape Town has a high prevalence of dental disease and tooth loss $[24,30]$. The loss of teeth, especially of the anterior teeth, was not linked to a poorer oral health-related quality of life in this population.

In this study, there was no difference in the OHRQoL for those who had a functional dentition or those who were fully edentulous, even though several studies in the literature 
support a lower OHRQoL in relation to increased partial tooth loss [31,32] (Table 3. While there is no simple explanation for this finding, it can be speculated that having teeth affected by oral disease leads to discomfort in daily life or that the presence of a denture is seen to be far more pleasing than the presence of dental pain. Previous studies from our group show a high degree of unmet dental treatment needs in the studied population; as such, potential inflammation, loose teeth, pain, and general discomfort have probably influenced the OHRQoL in the studied population $[30,33]$.

Another factor to be considered is the potential perception of dental extraction as the ultimate solution for oral disease in this population sample. Our sample represents an underprivileged community that has limited access to healthcare. In addition, the practice of the extraction of healthy maxillary incisors is highly accepted from a young age $[34,35]$. Thus, the studied sample may have a different perception of oral health, whereby having teeth extracted is normalised and considered a permanent and beneficial solution for oral problems. Partially dentate subjects have probably experienced pain, gingival bleeding, and tooth mobility, which would have negatively impacted their OHRQoL. This correlates with the high level of edentulousness in the Western Cape province, as people have accepted this norm across generations, and edentulous subjects seem to be generally more satisfied than those who have teeth that cause discomfort [36].

The studied sample has limited access to oral health preventative services. The subjects not seeking dental care displayed six times higher odds of experiencing a dental impact than those seeking dental care. Hence, it is conceivable that the absence of regular dental visits leads to symptomatic rather than preventive treatment. Those with moderate tooth loss may have experienced repeated pain or may have traumatic experiences while waiting for treatment for long periods at free dental facilities. Thus, having teeth extracted might be a relief, leading to a higher perceived OHRQoL score. In a study by Ayo-Yusuf et al. [37], oral pain affected $19.4 \%$ of an adult South African sample. In low socioeconomic areas, nearly $21 \%$ of those who experienced pain over the previous 6 months did not do anything to relieve it, suggesting a limited access to oral care.

In this community, oral health has a low value, as evidenced by the low OIDP odds of disease and the high prevalence of disease and tooth loss presented in previous studies.

\section{Limitations}

The presence of more females than males in the study could have resulted in women having a better OHRQoL than men since the study was conducted during the week, and most women in the study area are unemployed [38]. This tool was not tested for intrarater reliability for this study.

\section{Conclusions}

Within the limitations of this study, it can be concluded that tooth loss does not have an impact on the OHRQoL of these subjects. There was no difference in the reported odds of experiencing at least one oral impact for participants with the loss of their four anterior teeth, the loss of their posterior occlusal pairs, or with various teeth present in their mouths. The presence or absence of dentures did not cause a difference in the odds of reporting at least one oral impact. Women experienced higher odds of experiencing an oral impact compared to the male participants. The participants who had no self-perceived oral health satisfaction had higher odds of experiencing an oral impact than the participants with excellent, good, fair, and poor self-reported oral health. Those subjects who did not seek help due to a lack of funds had very high odds of experiencing at least one impact.

Author Contributions: Conceptualisation, U.M.E.C., R.T.E., T.E.M. and F.K.-D.; methodology, F.K.-D., A.P.K., C.C.P. and A.C.; writing—original draft review and editing, F.K.-D.; writing-original draft preparation, F.K.-D.; formal analysis, F.K.-D., A.C.; funding acquisition, R.T.E. and T.E.M.; data curation, R.T.E. and T.E.M.; project administration, validation, and resources, A.P.K. All authors have read and agreed to the published version of the manuscript. 
Funding: This project results from the Medical Research Council of South Africa's funding in terms of the MRC's Flagship's Awards Project SAMRC-RFA-UFSP-01-2013/VMH.

Institutional Review Board Statement: The study was conducted according to the guidelines of the Declaration of Helsinki and the Ethics Committee approved the study of the Faculty of Health and Wellness Sciences of the Cape Peninsula University of Technology (N14/01/003a).

Informed Consent Statement: Informed consent was obtained from all subjects involved in the study.

Acknowledgments: We would like to thank all the participants of this study. We would like to thank Wasiefa Jordan for the data collection.

Conflicts of Interest: The authors declare no conflict of interest. The funders had no role in the design of the study; in the collection, analyses, or interpretation of data; in the writing of the manuscript, or in the decision to publish the results.

\section{References}

1. Petersen, P.E.; Yamamoto, T. Improving the oral health of older people: The approach of the WHO Global Oral Health Programme. Community Dent. Oral Epidemiol. 2005, 33, 81-92. [CrossRef]

2. Yoshihara, A.; Suwama, K.; Miyamoto, A.; Watanabe, R.; Ogawa, H. Diet and root surface caries in a cohort of older Japanese. Community Dent. Oral Epidemiol. 2020, 00, 1-8. [CrossRef]

3. Kateeb, E.; Momany, E. Dental caries experience and associated risk indicators among Palestinian pregnant women in the Jerusalem area: A cross-sectional study. BMC Oral Health 2018, 18, 170. [CrossRef]

4. Hariyani, N.; Spencer, A.J.; Luzzi, L.; Do, L.G. Root caries experience among Australian adults. Gerodontology 2017, 3, 376-418. [CrossRef]

5. Martins-Júnior, P.A.; Marques, L.S. Clinical implications of early loss of a lower deciduous canine. Int. J. Orthod. 2012, 23, 23-27.

6. Geissler, C.; Bates, J.F. The nutritional effects of tooth loss. Am. J. Clin. Nutr. 1984, 39, 478-489. [CrossRef]

7. Allen, P.F. Assessment of oral health related quality of life. Health Qual. Life Outcomes 2003, 1, 40. [CrossRef]

8. Fontijn-Tekamp, F.; Slagter, A.; Van Der Bilt, A.; Hof, M.V.T.; Witter, D.; Kalk, W.; Jansen, J. Biting and Chewing in Overdentures, Full Dentures, and Natural Dentitions. J. Dent. Res. 2000, 79, 1519-1524. [CrossRef] [PubMed]

9. Ibiyemi, O.; Idiga, E. Tooth loss among the elders in an inner city area of Ibadan, Nigeria. Gerodontology 2017, 34, $264-271$. [CrossRef] [PubMed]

10. Steele, J.G.; Sanders, A.E.; Slade, G.D.; Allen, P.F.; Lahti, S.; Nuttall, N.; Spencer, A.J. How do age and tooth loss affect oral health impacts and quality of life? A study comparing two national samples. Community Dent. Oral Epidemiol. 2004, 32, 107-114. [CrossRef] [PubMed]

11. Feldens, C.A.; Dullius, A.I.D.S.; Kramer, P.F.; Scapini, A.; Busato, A.L.S.; Vargas-Ferreira, F. Impact of malocclusion and dentofacial anomalies on the prevalence and severity of dental caries among adolescents. Angle Orthod. 2015, 85, 1027-1034. [CrossRef]

12. Al-Omiri, M.; Karasneh, J. Impacts of missing upper anterior teeth on daily living. Int. Dent. J. 2009, 59, 127-132. [CrossRef] [PubMed]

13. Porter, J.; Ntouva, A.; Read, A.; Murdoch, M.; Ola, D.; Tsakos, G. The impact of oral health on the quality of life of nursing home residents. Health Qual. Life Outcomes 2015, 13, 102. [CrossRef]

14. Wang, M.; Xue, F.; He, J.; Chen, J.; Chen, C.; Raustia, A. Missing Posterior Teeth and Risk of Temporomandibular Disorders. J. Dent. Res. 2009, 88, 942-945. [CrossRef]

15. Gerritsen, A.; Allen, P.F.; Witter, D.J.; Bronkhorst, E.M.; Creugers, N.H.J. Tooth loss and oral health-related quality of life: A systematic review and meta-analysis. Health Qual. Life Outcomes 2010, 8, 126. [CrossRef] [PubMed]

16. Haag, D.; Peres, K.; Balasubramanian, M.; Brennan, D. Oral Conditions and Health-Related Quality of Life: A Systematic Review. J. Dent. Res. 2017, 96, 864-874. [CrossRef] [PubMed]

17. Adibi, P.; Keshteli, A.H.; Saneei, M.; Saneei, P.; Savabi, O.; Esmaillzadeh, A. Relationship between Tooth Loss, Functional Dyspepsia and Gastro-Esophageal Reflux Disorder among Isfahani Adults. Arch. Iran. Med. 2016, 19, 123-130.

18. Patel, M.H.; Kumar, J.V.; Moss, M.E. Diabetes and tooth loss: An analysis of data from the National Health and Nutrition Examination Survey, 2003-2004. J. Am. Dent. Assoc. 2013, 144, 478-485. [CrossRef]

19. STATSSA. How Unequal is South Africa. Available online: http://www.statssa.gov.za/? $\mathrm{p}=12930$ (accessed on 8 March 2021).

20. Hobdell, M.; Tsakos, G.; Sprod, A.; Ladrillo, T.; Ross, M.W.; Gordon, N.; Myburgh, N.; Lalloo, R. Using an oral health-related quality of life measure in three cultural settings. Int. Dent. J. 2009, 59, 381-388.

21. Naidoo, S.; Sheiham, A.; Tsakos, G. The relation between oral impacts on daily performances and perceived clinical oral conditions in primary school children in the Ugu District, Kwazulu Natal, South Africa. S. Afr. Dent. J. 2013, 68, $214-218$.

22. Matsha, T.E.; Hassan, M.S.; Kidd, M.; Erasmus, R.T. The 30-year cardiovascular risk profile of South Africans with diagnosed diabetes, undiagnosed diabetes, pre-diabetes or normoglycaemia: The Bellville, South Africa pilot study. Cardiovasc. J. Afr. 2012, 23, 5-11. [CrossRef] 
23. Erasmus, R.T.; Soita, D.J.; Hassan, M.S.; Blanco-Blanco, E.; Vergotine, Z.; Kengne, A.P.; Matsha, T.E.; Kegne, A.P. High prevalence of diabetes mellitus and metabolic syndrome in a South African coloured population: Baseline data of a study in Bellville, Cape Town. S. Afr. Med. J. 2012, 102, 841-844. [CrossRef] [PubMed]

24. The World Bank. Gini Index (World Bank Estimate)-South Africa. Available online: https://data.worldbank.org/indicator/SI. POV.GINI?locations=ZA\&most_recent_value_desc=false (accessed on 15 January 2021).

25. Von Elm, E.; Altman, D.G.; Egger, M.; Pocock, S.J.; Gøtzsche, P.C.; Vandenbroucke, J.P. The strengthening the reporting of observational studies in epidemiology (STROBE) statement: Guidelines for reporting observational studies. J. Clin. Epidemiol. 2008, 61, 344-349. [CrossRef] [PubMed]

26. Locker, D. Concepts of Oral Health, Disease and the Quality of Life. In Measuring Oral Health and Quality of Life, 1st ed.; Department of Dental Ecology, School of Dentistry, University of North Carolina: Chapel Hill, NC, USA, 1997; pp. 11-24.

27. Stock, C.; Jürges, H.; Shen, J.; Bozorgmehr, K.; Listl, S. A comparison of tooth retention and replacement across 15 countries in the over-50s. Community Dent. Oral Epidemiol. 2015, 44, 223-231. [CrossRef] [PubMed]

28. WHO. Oral Health Surveys: Basic Methods, 5th ed.; WHO: Geneva, Switzerland, 2016.

29. Tan, H.; Peres, K.; Peres, M. Retention of Teeth and Oral Health-Related Quality of Life. J. Dent. Res. 2016, 95, 1350-1357. [CrossRef] [PubMed]

30. Chikte, U.; Pontes, C.C.; Karangwa, I.; Kimmie-Dhansay, F.; Erasmus, R.; Kengne, A.P.; Matsha, T.E. Dental caries in a South African adult population: Findings from the Cape Town Vascular and Metabolic Health Study. Int. Dent. J. 2020, 70, 176-182. [CrossRef]

31. Gherunpong, S.; Tsakos, G.; Sheiham, A. Developing and evaluating an oral health-related quality of life index for children; the CHILD-OIDP. Community Dent. Health 2004, 21, 161-169.

32. Åstrøm, A.N.; Ekback, G.; Ordell, S.; Gulcan, F. Changes in oral health-related quality of life (OHRQoL) related to long-term utilization of dental care among older people. Acta Odontol. Scand. 2018, 76, 559-566. [CrossRef]

33. Chikte, U.; Pontes, C.C.; Karangwa, I.; Kimmie-Dhansay, F.; Erasmus, R.T.; Kengne, A.P.; Matsha, T.E. Periodontal Disease Status among Adults from South Africa-Prevalence and Effect of Smoking. Int. J. Environ. Res. Public Health 2019, 16, 3662. [CrossRef]

34. Morris, A.G. Dental mutilation in southern African history and prehistory with special reference to the "Cape Flats Smile". S. Afr. Dent. J. 1998, 53, 179-183.

35. Russell, S.L.; Gordon, S.; Lukacs, J.R.; Kaste, L.M. Sex/Gender Differences in Tooth Loss and Edentulism. Dent. Clin. N. Am. 2013, 57, 317-337. [CrossRef] [PubMed]

36. Friedling, L.J.; Morris, A.G. Pulling teeth for fashion: Dental modification in modern day Cape Town, South Africa. S. Afr. Dent. J. 2007, 62, 106-108.

37. Ayo-Yusuf, O.A.; Odukoya, O.O.; Olutola, B.G. Sociodemographic Correlates of Exclusive and Concurrent Use of Smokeless and Smoked Tobacco Products among Nigerian Men. Nicotine Tob. Res. 2013, 16, 641-646. [CrossRef] [PubMed]

38. Galal, S. South Africa: Unemployment Rate by Gender 2016-2020. [Online] Statista. 2021. Available online: https:/ /www.statista. com/statistics/1129142/unemployment-rate-by-gender-in-south-africa/ (accessed on 12 March 2021). 